\title{
Digital development trajectory as a tool for improving the quality of education
}

\author{
Roman Kupriyanov ${ }^{1 *}$, Alexei Semenov ${ }^{2,3,4}$, Vladimir Kondratiev ${ }^{4}$, and Polina Nikulina ${ }^{5}$ \\ ${ }^{1}$ Moscow City University, IT Department, Moscow, Russia \\ ${ }^{2}$ Lomonosov Moscow State University, Faculty of Mechanics and Mathematics, Department of \\ Mathematical Logic and Theory of Algorithms, Moscow, Russia \\ ${ }^{3}$ FRC "Computer Science and Control" of Russian Academy of Sciences, Axel Berg Institute of \\ Cybernetics and Educational Computing, Moscow, Russia \\ ${ }^{4}$ National Research University Higher School of Economics, Institute of Education, Department of \\ Educational Programs, Moscow, Russia \\ ${ }^{5}$ University of Sydney, Institutional Analytics and Data Science, Sydney, Australia
}

\begin{abstract}
The present article proposes an approach to using students' digital development trajectories to improve the quality of education. Designing a digital development trajectory has a positive effect on students' motivation and active participation in deciding on its formation. The goal of the study is to create a conception of using methods and approaches of educational data mining and machine learning in analyzing and predicting digital development trajectories to improve the educational process quality. Implementation of learning management systems with the opportunity to dynamically track students' academic performance allows timely correcting gaps appearing in students' knowledge and thereby reducing the risk of them falling behind in their study group. Recording the obtained results of completed assignments and interactions with learning management systems also benefits teachers who get an opportunity to receive feedback in an implicit form and account for gaps appearing in the curriculum in a processed and aggregated form. The analysis is conducted based on a database of additional education in a primary school (grades 1-3). The present study examines several scenarios of using a digital development trajectory in education including students' progress in an academic performance trajectory based on their grades, a trajectory in terms of time spent on solving problems to determine their complexity, and a heatmap for determining problematic areas and weak spots in each teacher's educational course. Based on educational data from a learning management system, the authors present a set of recommendations for teachers on the adaptation of their educational course to students' abilities promoting the increase of the overall quality of education.
\end{abstract}

Keywords: personal trajectory, data-driven education management, electronic portfolio, educational data mining.

\footnotetext{
*Corresponding author: kupriyanovrb@yandex.ru
} 


\section{Introduction}

The prospect of a complete transition to a digital educational process in which a student's interaction with educational materials and test assignments takes place in a learning management system (LMS) provides new opportunities to analyze a student's interaction with an educational course in real-time. At the present stage of their development, modern LMS [1] allow recording a large number of actions a student makes while using LMS including tracking the movement of their cursor between different elements of the web page. Applying educational data mining (EDM) and Big Data in Education approaches to these data can transform the educational process itself, lead to a rethinking of the classical approaches, and adapt the accumulated experience to increase the effectiveness of education [2].

All individual academic achievements of a student are stored in a special system - a portfolio of documents. Creating a portfolio allows solving important pedagogical problems: stimulating motivation for learning and developing the reflection and evaluation skills of future specialists [3]. A shortcoming of a document portfolio is that it provides an idea of a student's results but does not demonstrate the process of their professional and personal development, the variety of their creative activity, learning style, and interests [4].

A personal digital development trajectory is understood as a personal trajectory of the realization of each student's personal potential in education including individual profiles of competencies and trajectories of their development [5]. A personal digital development trajectory is based on numerous factors and considers a large number of parameters while the presence of previously formed digital trajectories of other students allows making corrections and executing timely interventions for new students to follow the existing basic digital development trajectories [6].

The opportunity to analyze and correct students' actions in real-time is especially relevant for primary school students. Building the interaction between a student and a teacher through the information space allows fully analyzing the entire history of their interactions in digital form including the textual data of comments and remarks on the results of assignments [7]. Working with such an array of data and creating a personal digital trajectory of students' development calls for the techniques of educational data mining and machine learning.

The present study aims to create a conception of using methods and approaches of educational data mining and machine learning in analyzing and predicting digital development trajectories to improve the educational process quality. To achieve the set goal, it is necessary to create an individual educational trajectory of a student, determine weak spots in an educational course, and identify patterns present in the educational course of each teacher.

\section{Methods}

The analysis of the educational process and identification of the ways to improve its quality can be carried out using the approach based on personal digital development trajectories [8]. The foundation of this approach is formed by the principle of intellectual data analysis focused on the search for patterns and creating prognostic models the input parameters in which can be presented by the evaluation of task completion, the time it took to complete the task, the number of repeated attempts to complete the task if the initial result is unsatisfactory, the correspondence of the repeated task to the comments received from a teacher, the sequence of actions performed when working on the task, and formalized characteristics of the lesson and tasks (the area of knowledge, keywords, the type of tasks). The proposed approach involves three steps: identifying similar groups of students, creating a prognostic model of academic performance, and developing feedback for students and teachers. 


\section{Results and discussion}

The analysis and design of educational trajectories were performed based on a dataset of additional education data from a primary school (grades 1-3) containing information on students' completion of courses including a list of lessons with titles, the grades obtained based on the results of completed assignments, and the time it took students to complete each task. The LMS was designed based on the Moodle platform [9] and included the following important fields in the database tables: lesson name, lesson type, lesson grade, student ID, teacher ID, and time spent on assignments. The system interface is presented in Figure 1.

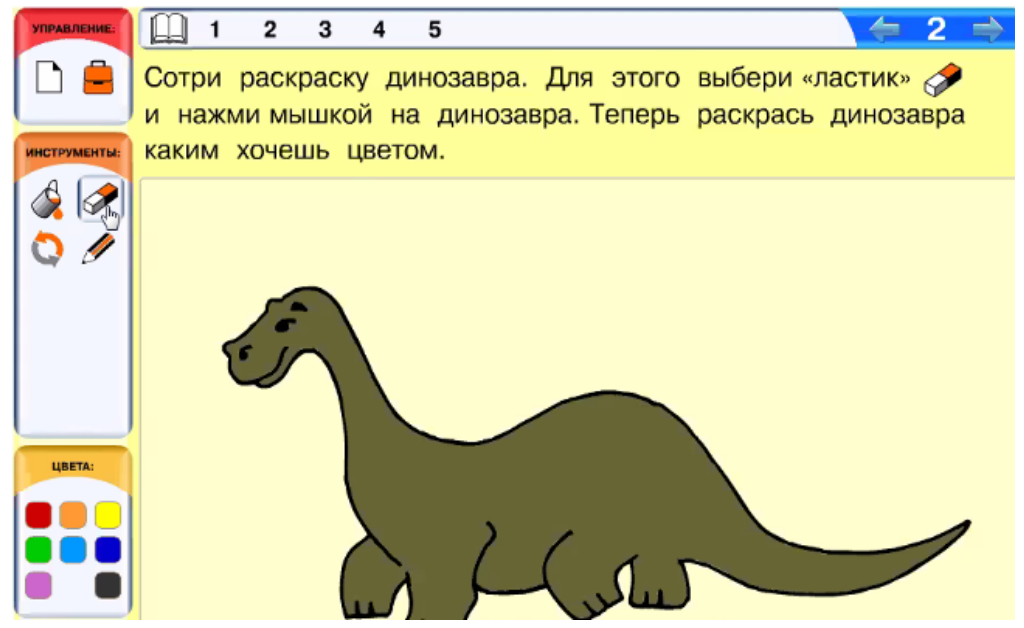

Fig. 1. A visual interface with a task for school students.

We examined three educational courses (academic disciplines) with the following number of students studying in each: the first course -460 students, the second course -572 students, the third course -584 students. The first course consisted of 21 lessons, the second included 30 lessons, and the third -23 lessons. In some lessons, students did not receive any grades. The overall sample included 18,374 recordings.

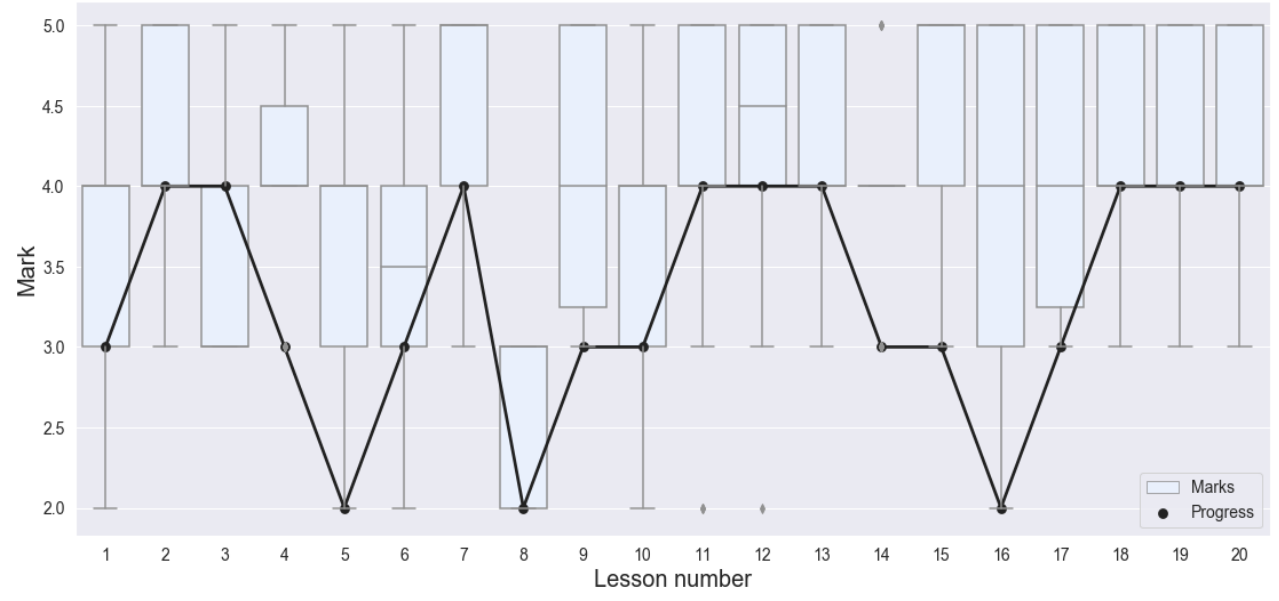

Fig. 2. Marks received by students as a result of completing the educational course.

The marks entered in the information system allow analyzing the quality of students' mastery of the material in the context of each lesson [10]. Figure 2 presents the level of grades 
received by students in one of the courses and the academic performance curve for that course for one of the students.

Based on the graph shown in Figure 2, a teacher can correct the material, change the approach and style of presentation, and reduce or increase the complexity of tasks for each lesson depending on the results achieved by students. For example, the assignment for Lesson 8 was challenging for all students resulting in the absence of positive grades. The graph also shows an example of a student's educational trajectory presenting all grades received during the course. The received unsatisfactory grades affect the subsequent study of related topics which, in turn, also leads to a negative result. Using the title and description of lessons in text analysis will allow selecting meaningful terms from the text and associating individual lessons with the subject classifier [11]. Thus, the knowledge gained by a student can be assessed and formalized in the context of the subject classifier.

In addition to grades for the completed tasks, it is also important to evaluate the time spent completing them. Based on the execution time, it is possible to determine the difficulty of the task for each student. Figure 3 presents a comparative analysis of average values (with distribution) of task execution time for each lesson. The data from the graph will allow a teacher to analyze the degree of complexity of tasks and the uniformity of task complexity distribution within the educational course.

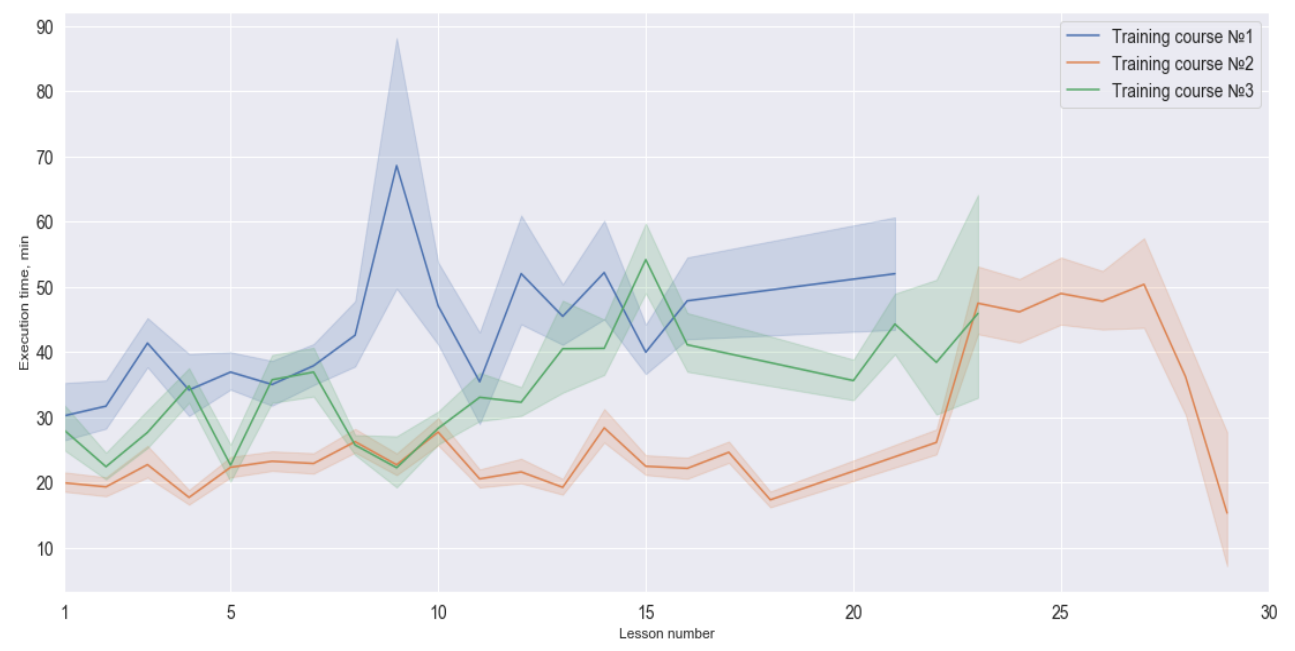

Fig. 3. The dynamic of students' mastery of the educational course depending on the time spent on it.

As illustrated by the chart, "Training course N1" has a significant peak demonstrating that one task was especially time-consuming for students. This fact has to be pointed out to the teacher to eliminate the situation that arose possibly either due to an excessive number of questions or due to the presence of several complex questions formulated incorrectly. Conducting a comparative analysis concerning each student compared to the average execution time will allow a teacher to detect difficulties with tasks in a timely manner and provide students with the necessary assistance in solving the task.

The use of students' digital trajectory makes it possible to perform a general analysis of the quality of lessons based on the received grades. Figure 4 presents a heatmap of grades received by students for completing lesson assignments in one academic semester. The grades are color-coded to characterize students' performance in each lesson and allow us to identify problem areas and weak spots in each teacher's educational course. 


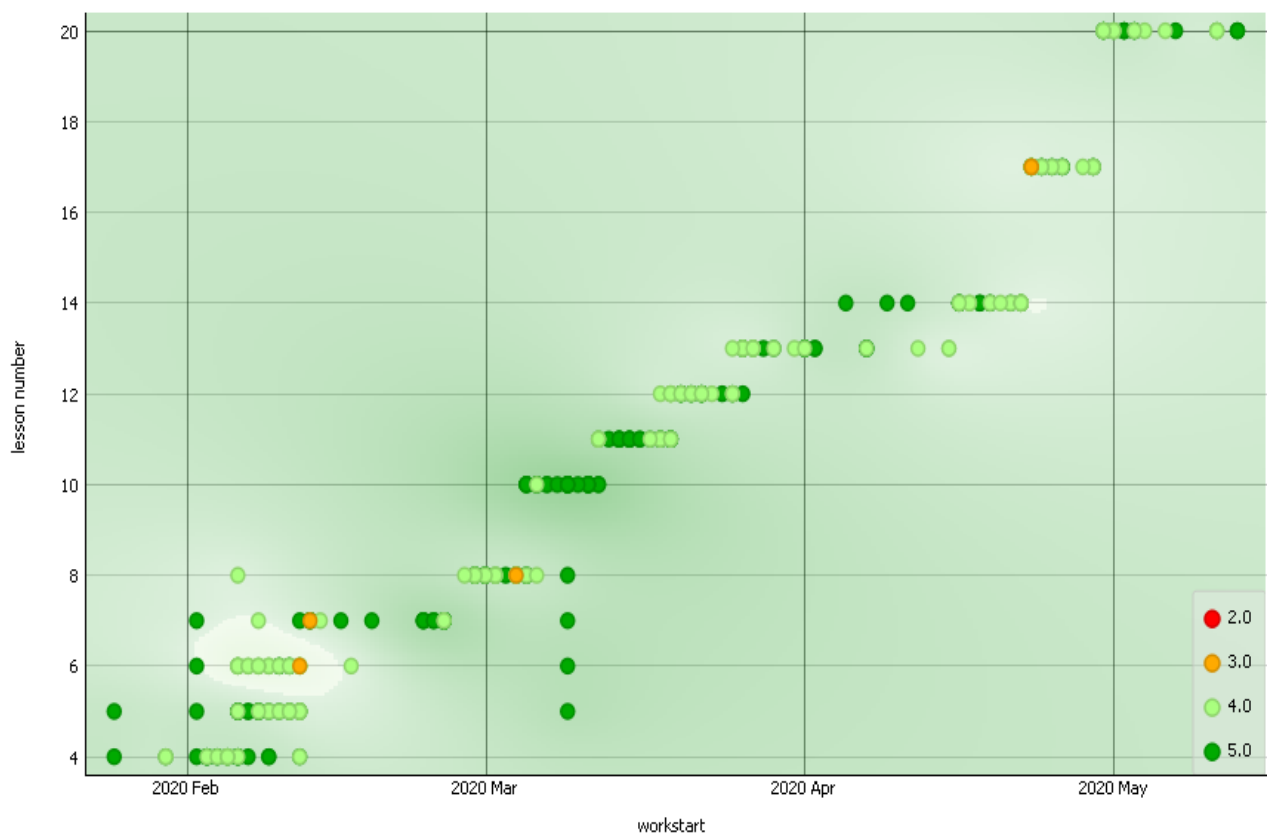

Fig. 4. A heatmap of grades received by students for completing lesson assignments in one academic semester.

Based on the received grades, the heatmap vividly illustrates several zones in need of closer attention from the teacher. The zone around Lesson 6 demonstrates that students' academic performance in completing the tasks is lower compared to related topics. This fact could be caused by a poor transition from the previous topic resulting in a decrease in the students' average academic performance. An example of the opposite situation can be seen around Lessons 10 and 11 where high academic performance is detected and the transition from one topic to another does not affect the grades. The presented heatmap also contains a timeline allowing for a comparative analysis of the teacher's educational course in the current and previous years. If the systematic problem with the emerging drops in the level of academic performance continues over time, the problem may reside not in the teaching material and students, but in the teacher requiring them to make extra efforts to take advanced training [12].

\section{Conclusion}

The implementation of the proposed approach will result in personal digital development trajectories of students intended both for students' evaluation of their perspectives and obtaining implicit feedback to improve the educational course [13]. The analysis of data on the process of students' completion of assignments allows tracking the logic of their actions and the time spent on each step in a timely manner, comparing the results of individual students with the average academic performance, ensuring well-timed assistance from the teacher, and identifying progression or regression in the trajectories of students' mastery of new material [14]. The sequence of decisions made by a student when completing an assignment, their reaction to feedback from the teacher, and the received comments about students' mistakes allow us to determine the character and temperament of the student, as well as their personal qualities. The obtained characteristics of students can be used and supplemented at the next stages of learning. The accumulation of information will contribute 
to understanding the characteristics of each student, their strengths and weaknesses, and the list of their problem areas of knowledge which will ultimately determine the best approach to each student [15].

\section{Acknowledgments}

The reported study was funded by RFBR, project number 19-29-14229.

\section{References}

1. A.H. Duin, J. Tham, Computers and Composition, 55, 102544 (2020). https://doi.org/10.1016/j.compcom.2020.102544

2. V.V. Utemov, P.M. Gorev, Kontsept, 6 (2018)

3. E.F. Zeer, L.N. Stepanova, Obrazovanie i nauka, 6 (2018)

4. E.V. Kondratenko, Vestnik of the Mari State University, 1(13) (2014)

5. S.S. Sokolov, M.N. Saveleva, A.V. Mitrofanova, Open education, 4 (2019)

6. N.L. Karavaev, E.V. Soboleva, Perspektivy nauki i obrazovaniia, 3(39) (2019)

7. S. Dukuzumuremyi, P. Siklander, International Journal of Research and Studies, 76(1), 165-174 (2018). https://doi.org/10.1016/j.tate.2018.08.010

8. R.T. Kompen, P. Edirisingha, X. Canaleta, M. Alsina, J.M. Monguet, Telematics and Informatics, 38, 194-206 (2019). https://doi.org/10.1016/j.tele.2018.10.003

9. L.M. Mukhametshin, L.L Salekhova. M.M. Mukhametshina, Vestnik of the Tatar State University of Humanities and Education, 2(56), 274-279 (2019)

10. R.B. Kupriyanov, A system for monitoring the dynamics of students' academic success based on data mining algorithms, in Proceedings of the II International Scientific Conference "Informatizatsiia obrazovaniia i metodika elektronnogo obucheniya", Siberian Federal University, 25-28 September 2018, Krasnoyarsk, Russia (2018)

11. A.I. Guseva, I.A. Kuznetsov, A.I. Guseva, I.A. Kuznetsov, The Use of Entropy Measure for Higher Quality Machine Learning Algorithms in Text Data Processing, in Proceedings of the 5th International Conference on Future Internet of Things and Cloud: Workshops (W-FiCloud), IEEE, 21-23 August 2017, Prague, Czech Republic (2017). https://doi.org/10.1109/FiCloudW.2017.84

12. I.A. Batalova, Nauka i shkola, 2, 73-79 (2019)

13. I. Ivanov, J. Cobo, M. Kosonogova, Procedia Computer Science, 172, 517-522 (2020). https://doi.org/10.1016/j.procs.2020.05.062

14. M. Rodrigues, L. Zárate, S. Isotani, Telematics and Informatics, 35(6), 1701-1717 (2018). https://doi.org/10.1016/j.tele.2018.04.015

15. D.M. Voronin, O.S. Mishina, O.A. Zavaltseva, Perspektivy nauki i obrazovaniia, 5(35) (2018) 